\title{
'Mad cow' scare threatens political link between food and agriculture
}

London. A decade of ministerial denials ended abruptly last week when the British government reluctantly acknowledged a possible link between consuming beef infected with bovine spongiform encephalopathy (BSE) and Creutzfeldt-Jakob disease (CJD), the fatal neurodegenerative disorder in humans.

The government continues to insist that British beef can be eaten with "confidence", and that the risk of contracting CJD remains "extremely unlikely". But the crisis in public confidence caused by last week's announcement has already prompted calls for changes in the structure of the Ministry of Agriculture, Fisheries and Food (MAFF), as well as the way that its Silent summer? Dairy herds may still be culled. research is linked to public policy deci-

sions. Both follow suggestions that MAFF cannot represent both the beef industry and consumers.

The government immediately banned the use of cattle and sheep offal in the animal food chain (it is already banned in feed for animals intended for human use). It has even been contemplating the destruction of a substantial proportion of the national dairy herd on the grounds that it could be harbouring BSE. But 20 countries, including most of the European Union, have still suspended British beef imports.

The government announcement, an untypically swift response to new research findings (see right), has led to panic both among the beef-eating public and alarm in Britain's $£ 2$ billion (US $\$ 3$ billion) beef industry, which could be facing collapse. It has also led to many questions about the government's handling of the entire BSE affair since it began in the mid-1980s, including the way that scientific evidence and advice is handled both within and between different government departments.

In the face of opposition claims of jeopardizing the nation's health, government ministers continue to insist that they have acted responsibly. One of the ministers at the centre of the crisis, Douglas Hogg, secretary of state for agriculture, says his responsibility to the public will always take priority over his duty to the agriculture industry. Stephen Dorrell, secretary of state for Health, has said that decisions relating to BSE are based on the advice of the government's 'independent' 13-member Spongiform Encephalopathy Advisory Committee (SEAC).

SEAC is at the centre of the latest, as well as previous 'BSE-related' incidents. Its

\author{
IMAGE \\ UNAVAILABLE \\ FOR COPYRIGHT \\ REASONS
}

members are drawn from a number of research disciplines, and periodically advise the government on BSE policy after reviewing the latest research. It was advice from
London. The British government's announcement last week that that there may be a link between bovine spongiform encephalopathy (BSE) and Creutzfeldt-Jakob disease (CJD) is based on reports of 10 cases of a previously unrecognized variant of CJD.

The 10 cases all showed first symptoms within the last two years, the average age being between 26 and 27 , with two in their late teens, and one aged 42 . Two patients are still alive.

The new strain seems to be a clinicopathological variant of conventional CJD, with an unusual pathology closer to that of the human disease kuru than that of sporadic or iatrogenic CJD. Furthermore, the clinical signs are more similar to kuru, with more ataxia than dementia, a characteristic that is also true of iatrogenic rather than sporadic CJD.

It is not clear that this new variant of CJD is, in fact, BSE. But the fact that its pathology has never been seen before, either in the United Kingdom or elsewhere, as well as the unusual age grouping - CJD is rarely found in individuals under the age of 30 - have both led the UK Spongiform Encephalopathy Advisory Committee (SEAC) to its conclusion that a new risk
㝕 SEAC that led to a ban of the use in cattlefeed of sheep and cattle offal in 1989, on evidence that cattle developed BSE after eating sheep offal infected with scrapie.

Recently, 10 new cases of CJD, of an average age below - and unlike - previous cases, were notified to SEAC. The committee's members told the government that, "in the absence of any credible alternative", the new infections could be attributed to all the victims having eaten beef infected with BSE before the imposition of the 1989 offal ban. (On Monday, John Pattison, professor of virology at University College and Middlesex School of Medicine in London, and chairman of the advisory committee, confirmed that two further suspected cases were under investigation).

In the past, the government has pointed to the absence of clear biological evidence to justify its refusal to acknowledge a link between BSE and CJD. The fact such evidence has still to be found has led the government's critics to point out that an

\section{BSE: the questions that need answers}

factor has appeared.

According to SEAC, the best candidate for this new risk factor is possible exposure to the BSE agent before a ban on offal was introduced in 1989. But further experiments will need to be done to assess whether this is in fact BSE.

This uncertainty is linked to the fact that there remains a great deal of uncertainty about CJD, BSE and prion diseases in general. The exact nature of the infectious agent is mysterious. Once believed to be a virus, based on its extreme resistance to ionizing and UV radiation - only solvent and extreme heat can reduce infectivity - it was proposed as early as 29 years ago that the agent contained no nucleic acid (see Nature 214, 764; 1967).

The 'prion hypothesis', namely that the infectious agent is in fact an abnormal conformation of a naturally occurring protein that transforms the normally harmless prion protein into a protease-resistant dangerous form, is now close to being generally accepted.

The host prion protein, whose normal function remains unknown, is necessary for infection to occur; mice lacking the normal prion protein cannot be 


\section{Food/agriculture link threat}

-(from previous page) earlier comprehensive offal ban in the human and animal food chain would not have created the present panic, nor imperilled the beef industry.

Erik Millstone, a senior lecturer and food policy specialist at the Science Policy Research Unit at the University of Sussex, is critical of SEAC. The government, he says, used SEAC's cautiously-worded advice to delay taking effective action. SEAC members, he adds, should have spoken out, instead of remaining silent. "Two months ago, Dorrell said that the likelihood of a link between BSE and CJD was 'inconceivable'. But I didn't hear any scientist say, 'no minister, that is not correct'." SEAC members ideally, he adds, should also include representatives of, "not just industry", but also consumer groups.

Millstone is one of a number of commentators calling for the break-up of MAFF on the grounds that a 'superministry' cannot protect the interests of both the agriculture industry and consumers when there is a direct conflict of interest between the two.

Under the existing arrangement, the agriculture industry is very much the senior partner within MAFF, says David Millar, a lecturer in media studies at the University of Stirling, who heads a research group into the

-infected, as no additional abnormal form can be produced. Recent experiments have shown that it is possible to propagate the abnormal, protease-resistant form of the prion protein in cell-free systems, and that even 'strain' properties can be faithfully reproduced in such in vitro assays.

But the story does not stop there. We know that there is a genetic predisposition for susceptibility to prion diseases, and a paper in this issue suggests that other cells may also be involved in the neurotoxic effects of the abnormal form (see page 345).

Furthermore, very little is also known about how, in cases of BSE, the prion particle moves from the digestive system to the brain. One suggestion is that it travels across the gut, via the lymphatic system, to the spleen, and then via the nerves innervating the spleen to the spinal cord and brain. A possible involvement of the immune system is also suggested by microglial involvement in neurotoxicity.

The main questions now being asked are whether BSE can infect humans who have eaten infected beef, and whether these new cases of CJD are due to BSE. One experiment almost certainly under way at present, which would confirm whether these cases are due to BSE, political dimensions of the BSE affair. The food safety directorate, adds Millstone, "is the poor relation". This has been confirmed by Edwina Currie, a former conservative health minister, who complained last week that public health plays a subordinate role.

Both Miller and Millstone claim that MAFF directly influences the nature of BSE research in favour of the agriculture industry. Millstone points, for example, to the lack of a single MAFF-funded research project aimed at developing a test to determine the presence or absence of the BSE pathogen both in live animals and in carcass meat. Miller claims that one researcher involved in identifying BSE was explicitly prevented by MAFF from describing BSE as 'a scrapie-like disease'.

MAFF, says Miller, also carries considerable weight within government over issues that affect the agriculture industry. $\mathrm{He}$ points out, for example, that the ministry over-ruled the Department of Health in 1988 during a scare over salmonella in eggs, when Edwina Currie, as health minister, acknowledged the claims of many scientists "that most of the egg production in this country is now infected with salmonella".

Currie's statement led to plummeting egg sales and open conflict between the Depart-

would be to inject infectious material from the CJD patients into mice, in order to discover whether the clinico-pathology resembles that already well described for BSE in mice.

The British government has pledged more money towards prion research. But where should that money go? Research

\section{IMAGE UNAVAILABLE FOR COPYRIGHT REASONS}

Trouble spots: brain section showing white lesions of Creutzfeldt-Jakob disease.

into the precise nature of the infectious agent must be continued; if scrapie protein produced in the cell-free system were shown to infect mice, the 'protein only' prion hypothesis would be almost certain. Other research priorities are the need for more work into the precise route of infection, from exposure to disease onset, and into the genetic ment of Health - concerned at the implications for public health - and MAFF, which was worried about the damage to the poultry industry. MAFF gained the upper hand, says Miller and thus took over the coordination of the government's response.

"Very senior sources in the department of health have reported that MAFF put 'intense pressure' on the chief medical officer to say, 'forget about it, she was quite wrong, eggs are safe"', claims Miller.

Both the salmonella and BSE sagas have prompted calls for the creation of an independent food standards agency and the recreation of an independent food ministry which existed until a merger created MAFF in its current form in 1955.

Tom Blundell, chief executive of the Biotechnology and Biological Sciences Research Council, which spends $£ 2.4$ million (US\$3.75 million) each year on spongiform diseases, says the current BSE affair "certainly justifies another look at separating the regulatory role of MAFF in order to restore public confidence".

$\mathrm{He}$ adds that attention should focus on why public concern reached such high levels; in particular, the idea "shared by the public, but not by scientists" that "a scientific statement is law". Blundell, who is active in promoting the public understanding of science, says "a feeling for uncertainty" is essential towards understanding a subject such as the BSE/CJD relationship.

Ehsan Masood

factors influencing susceptibility.

More practical studies could include the development of early diagnostic tests for both humans and cattle. Therapeutic approaches are also an important goal; while antifungal drugs and polyanions at high doses inhibit transmission in mice, the side-effects are undesirable, and attempts to treat CJD patients with such ô drugs have not been successful.

Better methods to detect infectious prion particles need to be developed. The present detection systems of Western blotting or bioassay, based on injection into mice, are not very sensitive; the 'species barrier' between cattle and mice requires the equivalent of 10,000 times more of the BSE agent to be injected into a mouse than into a cow to produce the disease.

Transgenic mice expressing the bovine prion protein might provide a more sensitive assay for BSE in potentially infected tissues. Furthermore, biochemical or other direct detection methods would be particularly welcome.

More needs to be done to assess whether these 10 cases are indeed due to BSE, and if so what the potential number of future cases might be. But SEAC remains convinced that measures taken over the past 7 years mean beef is safer now than ever.
Kimberly Carr 